\title{
AA. VV., L'œuvre de Jean Bodin
}

\section{Michele Mastroianni}

\section{CpenEdition \\ Journals}

\section{Edizione digitale}

URL: http://journals.openedition.org/studifrancesi/33026

DOI: 10.4000/studifrancesi.33026

ISSN: 2427-5856

\section{Editore}

Rosenberg \& Sellier

\section{Edizione cartacea}

Data di pubblicazione: 1 décembre 2005

Paginazione: 627-628

ISSN: 0039-2944

\section{Notizia bibliografica digitale}

Michele Mastroianni, «AA. vv., L'œuvre de Jean Bodin», Studi Francesi [Online], 147 (XLX | III) | 2005, online dal 01 novembre 2015, consultato il 19 avril 2021. URL: http://journals.openedition.org/ studifrancesi/33026 ; DOI: https://doi.org/10.4000/studifrancesi.33026

Questo documento è stato generato automaticamente il 19 avril 2021.

\section{(c) (†)}

Studi Francesi è distribuita con Licenza Creative Commons Attribuzione - Non commerciale - Non opere derivate 4.0 Internazionale. 


\title{
AA. VV., L'œuvre de Jean Bodin
}

\author{
Michele Mastroianni
}

\section{NOTIZIA}

AA. VV., L'œuvre de Jean Bodin, «Actes du colloque tenu à Lyon à l'occasion du quatrième centenaire de sa mort: 11-13 janvier 1996», publiés sous la direction de GABRIEL-ANDRÉ PÉROUSE, NICOLE DOCKÈS-LALLEMENT et JEAN-MICHEL SERVET, Paris, Champion («Colloques, Congrès et Conférences sur la Renaissances», 41), 2004, pp. 533.

1 Con un ritardo di otto anni (ma l'attesa eccessiva nella pubblicazioni degli atti dei convegni si va sempre più diffondendo, per ragioni in genere economiche) escono gli atti del Colloque Bodin del 1996. Si tratta di un corpus di contributi estremamente ricco e interessante, di cui è difficile dare qui conto singolarmente, per cui ci si limita ad elencare i titoli degli interventi. Gli approcci e le metodologie impiegati sono molteplici. Evidendemente La République è al centro degli interessi, e vengono analizzate le conseguenze non solo politiche ma anche economico e finanziarie della nuova concezione dello stato in essa espressa (ma vengono tenute presenti altre opere, anche quella Démonomanie des sorciers che ebbe una straordinaria diffusione a livello europeo). Gli «Atti» sono suddivisi in tre sezioni. In una prima sezione (Pouvoir, pp. 17-166) sono raccolte le comunicazioni che sondano le ricadute politiche e filosofiche della riflessione di Bodin sulla nozione di sovranità e di giustizia: Christian BRUSCHI, «Mesnage» et République (pp. 19-38), Béatrice PÈRIGOT, La notion de «République» chez Bodin (pp. 39-54), Guy LE THIEC, L'empire ottoman, modèle de monarchie seigneuriale dans l'œuvre de Jean Bodin (pp. 55-76), Jean-P. JOUBERT, Bodin et la théorie des relations internationales (pp. 77-99), Louis Augustin BARRIÈRE, Jean Bodin et le droit pénal (pp. 101-125), Nicole DOCKÈsLALLEMENT, Les républiques sous l'influence des nombres: le hasard et la nécessité chez Jean Bodin (pp. 127-149), Fernand HALLYN, Kepler lecteur de Bodin: la «Digressio politica» de l'«Harmonice mundi» (pp. 151-166). La seconda sezione (Pouvoir et économie, pp. 167-352) è consacrata alle teorie economiche di Bodin e alle ricadute sulla politica finanziaria ispirata a tali teorie: Nicola PANICHI, Danaé et Jupiter. De la politique à l'«œconomie 
politique»: Bodin et Montchrestien (pp. 169-206), Alain MARCIANO, Entre humanisme et mercantilisme: une approche par l'économie constitutionnelle de la «République» de Jean Bodin (pp. 207-235), Emmanuel THIVEAUD, Finances et souveraineté dans «Les six Livres de la République» de Jean Bodin (pp. 237-257), Jérôme BLANC, Forcer la vertu. Jean Bodin face au souverain faux-monnayeur (pp. 259-284), Michel LUTFALLA, Inflation et endettement: l'éternelle actualité de Jean Bodin (pp. 285-292), Philippe DESAN, Jean Bodin et l'imaginaire de la monnaie (pp. 293-304), Bernard BOBÉ, Jean Bodin et les origines françaises de la pensée fiscale d'Adam Smith (pp. 305-331), LAURE CHANTREL, Une relecture des travaux de Jean Bodin sur la fiscalité à pertir des comptes rendus des États généraux de 1560 à 1588 (pp. 333-352). In una terza sezione infine (Unité et diversité, pp. 353-515) viene ricostruito il quadro culturale in cui si muove Bodin, tenendo conto di quella che i curatori definiscono «l'évolution des coupures et de l'institutionnalisation des savoirs entre le XVI et la fin du XXe siècle»: Ann BLAIR, La philosophie naturelle dans l'œeuvre de Jean Bodin (pp. 355-365), Marie-Dominique COUZINET, La philosophie morale de Jean Bodin dans le «Paradoxe» de 1596. Hypothèse de lecture (pp. 367-383), Pierre LARDET, Nations et mémoire: les «vestiges de la langue» dans la «Methodus» de Jean Bodin (1566) (pp. 385-402), Michel REuLos, la mise en ceuvre par Jean Bodin de ses sources juridiques (pp. 403-409), Jacques SoLÉ, Le comparatisme historique et géographique dans la «République» de Jean Bodin (pp. 411-418), Claude-Gilbert DUBOIS, Les «esprits»: considérations sur la pneumatologie de Jean Bodin dans «De la Démonomanie des sorciers» (1580) (pp. 419-429), Voichita-Maria SASU, Jean Bodin: hantise du satanisme (pp. 431-445), Marc VENARD, Jean Bodin et les sorciers. La «Démonomanie» est-elle une aberration dans l'oeuvre de Jean Bodin? (pp. 447-458), G. HEINSOHN et O. STEIGER, Inflation et sorcelleri: un nouvel examen du cas de Jean Bodin (pp. 459-483), Jacques BIROUSTE, L'énigme d'anthropologie religieuse dans le «Colloquium heptaplomeres» (pp. 485-515). 